http://revped.ise.ro

Print ISSN 0034-8678; Online ISSN: 2559 - 639X

\title{
ANALYSIS OF THE SCHOOL ENVIRONMENT FROM THE PERSPECTIVE OF THE STUDENTS' STRESS
}

O ANALIZĂ A MEDIULUI EDUCATIV DIN PERSPECTIVA FACTORILOR DE STRES LA ELEVI

\section{Angelica MIHĂILESCU}

\author{
Journal of Pedagogy, 2017 (2), 61 - 73 \\ https://doi.org/10.26755/RevPed/2017.2/61
}

The online version of this article can be found at: http://revped.ise.ro/category/2017-en/

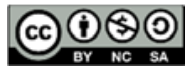

This work is licensed under the Creative Commons Attribution-NonCommercial-ShareAlike 4.0 International License.

To view a copy of this license, visit http://creativecommons.org/licenses/by-nc-sa/4.0/ or send a letter to Creative Commons, PO Box 1866, Mountain View, CA 94042, USA

Published by:

\section{INSTITUTUL DE ȘTIINȚE ALE EDUCAȚIEI}

http://www.ise.ro/

Further information about Revista de Pedagogie - Journal of Pedagogy can be found at:

Editorial Policy: http://revped.ise.ro/editorial-policy/

Author Guidelines: http://revped.ise.ro/the-writer-guide-2/ 


\section{O ANALIZĂ A MEDIULUI EDUCATIV DIN PERSPECTIVA FACTORILOR DE STRES LA ELEVI}

\section{Rezumat}

\section{Angelica MIHĂlLESCU*}

Articolul de fa ă are ca obiectiv să aducă în aten ia profesorilor problematica expunerii elevilor la stres în mediul educativ. Abordarea stresului elevilor prin intermediul cercetării se dovedeşte încă insuficient explorată, dar poate deschide drumuri importante în educa ie, dat fiind interesul general pentru îmbunătă irea randamentului şi a climatului şcolar. Pentru a expune succint această temă, am recurs la analiza documentară şi la prezentarea unor exemple de cercetări care au avut ca temă, explicit sau într-un cadru mai amplu, identificarea efectelor factorilor de stres în mediul educativ. Dintre aceştia, am ilustrat teama de eşec, evaluarea, comunicarea în fa a unui public. Cuvinte-cheie: comunicarea în fa a unui public, evaluarea, factori de stres, stresul în mediul educativ, teama de eşec.

\section{Abstract}

The present paper aims at drawing attention on the stress levels students are exposed to in the educational environment. The study into the students'stress is insufficiently explored, and it can open new research directions in education given the general interest for the improvement of the school climate and effectiveness. In order to briefly present this topic we carried out document analysis and review of research that looks into the stress factors in education either as a study focus or in a wider perspective. Among these we highlight the fear of error, assessment and exams, public speaking.

Keywords: public speaking, assessment, stress factors, stress in education, fear of error.

\footnotetext{
* Cercet. şt. dr., Institutul de Ştiin e ale Educa iei, Bucureşti, România; angela_mihailescu@yahoo.com
} 


\section{Cadru general}

O mare parte dintre studiile care au în vedere problematica stresului în mediul şcolar, subliniază faptul că încă există pu ine cercetări care au abordat impactul stresului asupra elevilor. În general, se observă că interesul de investigare s-a îndreptat, în ultimii 20 de ani, mai curând către cercetarea stresului studen ilor în mediul academic (în domenii precum medicină, juridic, arte, sport, poli ie). Totuşi constatarea că o persoană este expusă stresului pe tot parcursul vie ii a orientat interesul de cercetare către toate etapele de vârstă şi de şcolarizare. Ce se întâmplă cu elevul? Madders (1987) observă, de exemplu, că principalele surse de stres ale elevilor din învă ământul primar provin din mediul şcolar. Cum ar trebui să se simtă un elev la şcoală astfel încât să aibă randament în învă are? Această întrebare a generat preocupări pentru analiza măsurii în care aspecte specifice influen ează învă area la elevi: anxietate, teamă, emo ii pozitive şi negative, stres, rela ii interpersonale, climatul clasei, inteligen ă socială, stimă de sine, introspec ie, autocontrol etc.

Modalită ile de abordare a stresului sunt interdisciplinare, acest aspect determinând complexitatea instrumentelor de analiză şi a metodelor de interven ie. Pentru a avea un punct de plecare în în elegerea acestui fenomen, putem porni de la aşteptările privind nevoile psihologice de bază - competen ă, autonomie, rela ia cu ceilal i-pe care fiecare persoană doreşte să şi le asigure, indiferent de vârsta pe care o are, observând, reflectând şi căutând solu ii pentru acestea pe tot parcursul vie ii. Un exemplu de analiză a acestor nevoi psihologice de bază în mediul şcolar este dat de scala de evaluare PNSE Psychological Need Satisfaction in Exercise Scale - concepută de Wilson, Rogers, Rodgers \& Wild (2006), din care selectăm câteva exemple de itemi: pentru competen ă - „Am încrederea că pot face exerci ii dintre cele mai dificile”; pentru autonomie - „Cred că pot lua decizii în timpul orelor”; pentru rela ia cu ceilal i - „Mă simt ataşat de colegii mei de clasă deoarece mă acceptă aşa cum sunt".

În cele ce urmează vom realiza o prezentare succintă a principalelor aspecte privind stresul elevilor în mediul şcolar şi vom da câteva exemple privind modalită ile de investigare a factorilor de stres. Considerăm că această abordare poate veni în sprijinul profesorilor care îşi pun întrebări în legătură cu impactul diferi ilor factori de stres asupra învă ării elevilor şi care doresc să aibă câteva date de referin ă pentru constituirea propriilor investiga ii la clasă.

1.1. Stresul este definit de specialişti ca interac iunea dintre un subiect şi mediul său de via ă, aceasta însemnând modul în care o persoană percepe anumite situa ii care îi sunt impuse şi modul în care reac ionează la acestea 
(Lazarus, 1966; Sutherland \& Cooper, 2010 ş.a..). În mediul educativ, stresul este definit ca reac ie a unei persoane fa ă de exigen ele şi sarcinile cărora trebuie să le facă fa ă, precum teste, examene, lucrări, prezentări orale etc. Această situa ie determină o persoană care înva ă să activeze diferite strategii pentru a putea face fa ă respectivelor provocări, astfel încât să-şi atingă cu succes obiectivele şi să aibă randament în învă are.

Diferite studii (Weinman, 1987) iau în considerare următoarele perspective asupra stresului: stresul ca stimul-condi iile stresante generează reac ii de adaptare a copilului şi pot fi datorate unor factori externi (monotonia, izolarea, lucru sub presiunea timpului, căldura, schimbarea bruscă a mediului de via ă) sau interni (dorin e, impulsuri) (Cramer \& Block, 1998); stresul ca răspuns copilul reac ionează prin diferite comportamente, utilizând diferite mecanisme de apărare, observabile încă din perioada preşcolară (Cramer \& Block, 1998); stresul ca percep ie şi evaluare a unei situa ii ce reprezintă o amenin are pentru siguran a proprie-copilul evaluează şi compară propriile capacită i de a face fa ă stresului cu intensitatea percepută a stresorului, iar diferen ele dintre provocările experimentate şi încrederea în capacitatea lui de a le face fa ă generează experien a stresului (Alsop \& McCaffrey, 1993). Observarea unor elevi din învă ământul primar l-a determinat pe Madders (1987) să afirme că principala sursă de stres pentru copii provine din mediul şcolar şi să constituie o listă cu astfel de situa ii: e agresat de copiii mai mari; e ridiculizat în clasă; e ultimul care termină o sarcină; se mută într-o clasă/şcoală nouă; are teste şi examene; a luat o notă proastă pe care trebuie să o comunice părin ilor; ajunge târziu la şcoală; trebuie să facă ceva în fa a unui public; e diferit de ceilal i prin ceva anume etc. În afara mediului şcolar, factorii de stres ai copilului identifica i de Madders se referă la: pierderea unui părinte (prin divor sau deces); s-a pierdut sau a fost lăsat singur; certurile dintre părin i; mersul la dentist sau la spital; pierderea sau distrugerea unor lucruri; apari ia unui copil nou în familie.

1.2. Pentru identificarea factorilor de stres specifici mediului educativ, au fost elaborate diferite scale de analiză. Acestea au avut ca scop inventarierea situa iilor de stres şi validarea/adaptarea listei constituite prin intermediul studiilor şi cercetărilor de teren, ce au avut ca public intă, ini ial, studen ii, apoi elevii, de la vârste mari până la primele perioade din via a unui copil. De exemplu, în scala de analiză a factorilor de stres (stresori) realizată de Holmes şi Rahe (The Social Readjustment Rating Scale An inventory of common stressors - ACC, 2015) sunt incluse diferite aspecte, precum începerea sau încheierea studiilor academice, vacan a, schimbarea şcolii/ a mediului de via ă. 
În mediul educativ, pot fi identificate două categorii de factori de stres: factori interni, genera i de autoexigen ă, aşteptări înalte, dorin a de păstrare a controlului şi efortul depus pentru a atinge acest scop; factori externi, genera i de mediul în care se află persoana, referitoare la data de depunere a unor lucrări, trecerea unor teste sau examene într-un timp determinat, realizarea unor lucrări în grup, expunerea unor lucrări în fa a colegilor, neîn elegerea unor no iuni, con inuturi predate în clasă, timp limitat pentru a se achita de obliga iile şcolare/academice. Barazza (2008) constituie următoarea listă de factori de stres din mediul educativ academic: competi ia în cadrul grupului; supraîncărcarea; excesul de responsabilită i (interac iunile din clasă prin formularea şi răspunsul la întrebări, participarea la colocvii etc.); întreruperea lucrului; ambient fizic dezagreabil; lipsa de stimulare; timp limitat pentru realizarea unei lucrări; probleme sau conflicte cu profesorii; probleme sau conflicte cu colegii; evaluările; tipul de sarcină de lucru cerut de profesor.

1.3. Studiile anterior citate men ionează că reac iile la stres se pot manifesta în planul cognitiv şi emo ional, fizic (al sănătă ii) şi comportamental. În plan cognitiv şi emo ional se pot observa reac ii de nelinişte şi hiperactivitate, triste e, anxietate permanentă, dificultă i de concentrare, dificultă i de gândire (minte goală), probleme de memorie (uitare frecventă), stare de iritabilitate şi discu ii în contradictoriu, teama de a nu reuşi să-şi îndeplinească obliga iile şcolare, slabă motiva ie pentru învă are, nelinişte şi/sau dorin a de a plânge în mod frecvent. La nivel fizic, al sănătă ii, pot apărea alte reac ii al stres: stări de somnolen ă, oboseală, dureri de cap, dureri de stomac, colon iritabil, scrâşnetul din ilor, dureri de spate, tahicardie, creşterea sau pierderea poftei de mâncare, scăderea imunită ii (răceli frecvente), dificultă i de somn (insomnie sau coşmaruri). În ceea ce priveşte planul comportamental, au fost identificate alte forme de reac ii la stres: tendin a frecventă de a discuta cu ceilal i, dorin a de singurătate sau de izolare, recursul la medicamente/alte tipuri de substan e (pentru a sta treaz, pentru a dormi), preferin a pentru alte activită i în locul studiului, dificultă i în a începe să lucreze, plecatul de la ore, pierderea interesului fa ă de activită i pe care le făcea în mod normal, apatie.

Analizând aceste reac ii, se constată o apropiere între manifestările stresului şi cele care presupun comportamente conflictuale, agresive. Acestea se pot manifestă între egali (prin deranjarea celorlal i, excluziune socială şi/sau violen ă verbală) sau între elevi şi profesor (prin violen a verbală a elevului fa ă de profesor, sau a profesorului fa ă de elev etc.) (a se vedea şi inventarul celor 42 de situa ii conflictuale în şcoli descris în Ceballos et al., 2002).

Pentru sus inerea afirma ie privind rela ia dintre stres şi violen ă, date de cercetare privind violen a în şcoală sunt semnificative. Potrivit unui studiu al 
Institutului de Ştiin e ale Educa iei privind violen a în şcoală (2016), elevii semnalează faptul că violen a verbală este cea mai frecventă în mediul şcolar. Atitudinile elevilor fa ă de profesori asociate cu violen a în şcoală, cel mai frecvent men ionate, constau în ignorarea mesajelor transmise de aceştia, refuzul îndeplinirii sarcinilor, urmate de atitudini ironice/sarcastice, injurii, jigniri, amenin ări sau agresiune nonverbală (gesturi, priviri amenin ătoare etc.). Din perspectiva cauzelor violen ei şcolare, atât profesorii, cât şi elevii consideră că lipsa de interes şi de motiva ie a elevilor pentru învă are este cauză a comportamentelor neadecvate ale elevilor. În acelaşi sens, alte cauze sunt: reac ia elevilor la impunerea for ată a autorită ii profesorilor, dificultă ile în comunicarea cu profesorii, reac ia elevilor fa ă de evaluări ale profesorilor considerate neobiective. Din perspectiva profesorilor, cauzele violen ei elevilor se situează şi în alte registre de analiză: preluarea unor modele de rela ionare din familie sau din diferite grupuri (gaşcă de cartier, grup de prieteni etc.), influen a negativă a mediului virtual (Internet). Consilierii şcolari consideră că cei mai importan i factori individuali care pot determina manifestări agresive sunt: toleran ă scăzută la frustrări, insuficienta dezvoltare a abilită ilor de comunicare şi de rela ionare în grup, instabilitate emo ională, imagine de sine negativă.

1.4. Mecanismele de apărare sunt definite ca opera ii cognitive cu func ie de protec ie a unei persoane fa ă de efectele provocate de anxietate (Cramer, 1987). Acestea reprezintă răspunsuri „adaptative” dezvoltate de o persoană încă din copilărie, pentru a putea func iona în situa ii care îi provoacă anxietate, asigurându-şi echilibrul psihologic; sunt permanent dezvoltate, de la strategiile simple ale copilului la cele mai complexe ale adultului (Cramer \& Block, 1998).

Potrivit studiilor lui Cramer (1987), mecanismele de apărare cunosc trei forme principale, anume: negarea - formă de apărare tipică pentru vârsta preşcolară, care presupune îndepărtarea aten iei de la stimuli considera i nocivi sau periculoşi, negându-le existen a (de exemplu, visatul cu ochii deschişi); proiec ia - utilizată de copii şi adolescen i, prin atribuirea către alte persoane a propriilor manifestări considerate neplăcute sau inacceptabile, cum ar fi sentimentele de ostilitate, de agresivitate, de suspiciune; identificarea presupune preluarea unor calită i sau caracteristici ale altor persoane pentru a-şi spori propria siguran ă şi stimă de sine; mecanismul este utilizat cu prioritate de adolescen i şi presupune confirmarea prin afiliere cu alte persoane. Chandler (1985) prezintă patru modele de răspuns a copilului la stres, care se pot manifesta în diferite grade, în func ie de axa activ-pasiv şi introvertitextrovertit: răspunsul dependent (lipsa de încredere în sine, dificultatea de a accepta critici, lipsa afec iunii, participare scăzută la activită i); răspunsul reprimat (sensibilitate crescută - se supără uşor, se simte rănit în sentimentele 
sale, temător în fa a unor situa ii noi, pu in încrezător în sine); răspunsul pasiv-agresiv (randament şcolar scăzut în mod frecvent, notele luate tind să scadă, au tendin a de a-şi amâna rezolvarea sarcinilor, pu in cooperan i, dezorienta i); răspunsul impulsiv (exigent, provoacă disconfort sau supărare în interac iunea cu ceilal i, cu temperament exploziv, lucrează neglijent).

O altă modalitate de descriere a răspunsurilor prin care o persoană reac ionează la situa ii stresante este cea a lui Moos \& Billings (1982): acceptare resemnată (acceptarea situa iei ca atare, senza ia că nu se poate face nimic); descărcarea emo ională (lipsa de control a emo iilor, exteriorizare intensă); căutarea de recompense alternative (compensarea frustrării resim ite prin căutarea altor surse de satisfac ie şi pentru a-şi asigura autonomia); evitarea cognitivă (evadarea într-o lume imaginară, visatul cu ochii deschişi, negarea situa iei stresante).

1.5. Problematica inciden ei stresului se regăseşte, de exemplu, în modelul de învă are a unei limbi străine construit de Krashen (1985), cunoscut ca „modelul monitorului”. Krashen introduce ipoteza influen ei pe care filtrul afectiv o are asupra achizi iei unei limbi străine (anxietate, motivare, atitudinea participan ilor etc.). De exemplu, dacă nivelul anxietă ii are valori mai scăzute, elevul înva ă mai uşor. În ceea ce priveşte stresul, se observă acelaşi proces: cu cât acesta este mai ridicat, cu atât învă area devine mai dificilă, elevul concentrându-se pe rezolvarea problemei emo ionale cu care se confruntă.

În situa ia în care profesorul identifică, în grupul de elevi, valori ridicate ale anumitor factori de stres cu impact asupra randamentului şcolar şi asupra climatului clasei, el va trebui să construiască un program de remediere. Selec ia de strategii trebuie să reflecte atât natura factorilor de stres, cât şi reac iile la stres manifestate de elevi (în plan cognitiv, emo ional, comportamental şi al sănătă ii fizice). Un punct de plecare în alegerea propriilor strategii de preven ie/ interven ie poate fi găsit în următoarea listă de recomandări, regăsite în diferite studii anterior citate: stimularea creierului şi pregătirea unui mediu pozitiv de lucru, ascultând muzică clasică sau ambientală; realizarea unor activită i care pot remonta fizic şi psihic; realizarea de efort fizic prin plimbări, sport sau activită i domestice (cură area camerei, ordonarea spa iului personal); mâncare sănătoasă; dormitul suficient; organizarea timpului, pregătirea orarului de studiu; anticiparea situa iilor stresante şi pregătirea pentru acestea, având aşteptări realiste; împărtăşirea emo iilor; evitarea sursele care distrag aten ia (de exemplu, verificarea telefonului); joaca cu un animal din casă sau cu o jucărie preferată etc. În Spania, de exemplu, cursurile de formare ini ială a viitorilor profesori din învă ământul primar cuprind o serie de elemente de pregătire pentru interven ii ameliorative asupra stresului la elevi: tehnici de 
relaxare şi de respira ie pentru a asigura starea de bine a copiilor; tehnici de concentrare; tehnici de reducere a anxietă ii. Tehnicile de control al emo iilor şi de autoreflec ie sunt, de asemenea, foarte utile, având impact atât asupra randamentului în învă are, cât şi asupra atmosferei din clasă. Şi în contextul sistemului de învă ământ românesc, o serie de strategii care au inciden ă şi asupra prevenirii stresului sunt incluse în modulele de management al clasei de elevi.

\section{Factorii de stres în mediul educa ional: cercetări, aplica ii şi programe specifice}

Prezentăm în continuare câteva exemple de cercetări care au abordat stresul în mediul şcolar, în mod direct, sau asociat cu alte teme. Analiza studiilor a permis sintetizarea unei imagini privind factorii de stres din mediul şcolar care se află cel mai adesea în aten ia specialiştilor, a profesorilor şi a formatorilor, pentru îmbunătă irea rezultatelor învă ării şi a climatului şcolar.

2.1. Cantitatea de informa ii de asimilat de către elevi sau studen $i$ reprezintă unul dintre factorii de stres asociat în mod direct cu mediul educativ. În acest sens cităm un studiu privind evaluarea nivelului de stres al elevilor unei şcoli de poli ie din sistemul de învă ământ românesc (Bora, 2007) arată că principalii factori de stres percepu i de elevi sunt cantitatea mare de informa ii de învă at (65\%) şi programul încărcat (24\%). Aproximativ jumătate dintre subiec ii care s-au autoevaluat relevă un nivel mediu de stres, iar aproximativ un sfert dintre elevi relevă un nivel ridicat de stres. Autoarea studiului concluzionează că elevii utilizează pu ine strategii adaptative active. O treime dintre aceşti preferă odihna ca metodă de adaptare la stres, în timp ce doar aproximativ un sfert dintre elevi aleg organizarea învă ării.

2.2. Examenele na ionale de capacitate şi bacalaureat sunt percepute la nivelul societă ii ca reprezentând două probe de evaluare cu mare impact asupra viitorului elevilor din România (OCDE, 2017). Contextul în care se realizează pregătirea pentru aceste tipuri de evaluare este caracterizat prin cantitate mare de informa ii de asimilat şi declararea unui nivel înalt de exigen ă, ceea ce generează un mediu considerat amenin ător şi o stare accentuată de incertitudine (Clinciu et al., 2008). Cercetarea efectelor evaluărilor sumative din învă ământul românesc a presupus luarea în calcul a eficacită ii generale ca factor pozitiv, şi a stresului şcolar ca factor negativ. Rezultatele cercetării pun în eviden ă că nu există diferen e semnificative de la un ciclu de învă ământ la altul în ceea ce priveşte factorul pozitiv. În schimb, pentru factorul negativ se înregistrează diferen e semnificative statistic: elevii de liceu sunt expuşi la un nivel mai crescut de stres şcolar, fa ă de nivelul anterior de învă ământ. 
Potrivit autorilor cercetării, în cadrul grupului de elevi participan i la studiu, nivelul de stres este mai scăzut în cazul băie ilor, comparativ cu fetele, iar matematica generează mai mult stres în compara ie cu limba maternă. Pe de o parte, evaluările prin examenele de capacitate şi bacalaureat creşte stima de sine şi reglează aşteptările legate de certificarea competen elor. Pe de altă parte, aceste forme de evaluare - care îi expun pe elevi la cel pu in un an de mare presiune şi efort pentru pregătire - accentuează stări de anxietate, depresie, şi afectează imaginea de sine (trăsăturile de personalitate influen ând percep ia valorii personale în acest proces de adaptare şcolară).

Actualitatea acestei teme de cercetare se regăseşte şi în studiul OCDE din 2017 care aduce în discu ie, într-un context mai larg de analiză, problema costurilor pe care tipurile de examinare din sistemul de învă ământ românesc le au asupra elevilor: „In România, evaluarea elevilor este dominată de examinări cu mize importante, care limitează procesul de învă are şi promovează o defini ie restrânsă a succesului. Plasarea învă ării în centrul evaluării va permite reechilibrarea acesteia şi recunoaşterea abilită ilor şi a intereselor tuturor elevilor, oferindu-le şansa să dea tot ce e mai bun" (OECD, 2017, p.15).

2.3. Teama vorbitului în public este un alt factor de stres frecvent întâlnit în sistemele de educa ie. Cercetări specifice arată că această teamă este resim ită de aproximativ $75 \%$ din popula ie, iar $32 \%$ dintre aceştia dovedesc un nivel crescut de anxietate în această situa ie (Bados, 2008). Teama elevului de a vorbi se poate manifesta, de exemplu, în situa ii care pot avea ca scop fie interac iunea verbală în context şcolar, fie evaluarea/examinarea.

O cercetare derulată la Facultatea de Educa ie din Zaragoza a avut în vedere participarea studen ilor la un program de reducere a anxietă ii fa ă de vorbitul în public, efectul acestuia fiind verificat prin intermediul unui chestionar de autoeficacitate (Orejudo, Fernández-Turrado, Briz, 2012). S-a plecat de la premisa că autoeficacitatea („self-efficacy”) are implica ii asupra efortului depus în învă are, asupra nivelului de rezisten ă în fa a eşecurilor sau asupra motiva iei intrinseci (Brown, Morrisey, 2004; Zimmerman, 2000). Aceasta este considerată un factor mediator al anxietă ii şi un factor motiva ional în situa ia de rezolvare a unor sarcini noi. Activitatea de evaluare a programului eviden iază că autoeficacitatea, alături de al i factori motiva ionali, poate influen a învă area comunicării orale, persoana respectivă putându-şi controla mai bine propria interven ie în situa ia vorbitului în public.

O altă cercetare derulată la Universitatea din Pais Vascoa fost structurată în jurul unui proiect inovator de formare a unor buni vorbitori, prin introducerea de strategii psihologice de control al anxietă ii comunicative în mediu academic (García-Ureta, Toral-Madariaga \& Murelaga-Ibarra, 2012). În cadrul proiectului 
au fost aplicate chestionare: de măsurare a dificultă ii percepute cu privire la o sarcină de realizat; de măsurare a anxietă ii (adaptat după inventarul anxietă ii - nivel competitiv conceput de Cox, Martens \& Russell, 2003); de măsurare a autoeficacită ii (prin metoda recomandată de Bandura, 1997); de măsurare a fluen ei verbale (versiunea propusă de García-Calvo, Sánchez, Sánchez \& Amado, 2011). lată câteva exemple de itemi: „simt că sunt capabil să fac fa ă dificultă ii situa iei”; ,mă pot concentra foarte bine”; ,ştiu clar ce am de făcut”; „mă simt bine în ceea ce fac” etc. Evaluarea ini ială a pus în eviden ă existen a unui grad mare de anxietate a participan ilor în legătură cu vorbitul în public. Datele de cercetare au relevat că abilită ile psihologice (autoeficacitatea şi controlul anxietă ii) şi disponibilitatea mentală ini ială şi pe parcursul comunicării sunt factori determinan i în dezvoltarea capacită ii de comunicare, ac ionând implicit asupra nivelului de stres perceput de studen i.

\subsection{Analiza diferen elor dintre fete şi băie i în ceea ce priveşte reac ia} la stresul din mediul şcolar constituie o variabilă luată în considerare în investigarea acestui fenomen. $O$ astfel de analiză a făcut parte dintr-o cercetare care a avut ca obiectiv ameliorarea condi iilor de lucru ale elevilor şi bunăstarea acestora în mediu şcolar (Esparbès-Pistre, Bergonnier-Dupuy \& CazenaveTapie, 2015). Aceasta s-a derulat la nivelul învă ământului secundar inferior şi superior în Fran a şi a luat în considerare variabile precum anul de studiu şi genul elevilor. Una dintre ipotezele de cercetare a plecat de la întrebarea dacă fetele, care sunt considerate mai emotive decât băie ii, sunt şi mai stresate în mediul şcolar. Astfel, a fost aplicat un chestionar sociocultural şi o scală de stres perceput, la fete şi băie i de 10-11 ani, respectiv 18-20 de ani (anul terminal al liceului). Rezultatele cercetării au pus în eviden ă faptul că un elev din trei este foarte stresat la colegiu sau la liceu, iar nivelul de stres creşte de la anul al şaselea de studiu şcolar până la anul terminal. Chiar şi în condi iile în care s-a constatat că fetele au o inteligen ă emo ională mult mai dezvoltată, datele de cercetare arată că acestea sunt totuşi mai stresate decât băie ii, indiferent de anul de studiu. Cauza acestei realită i se datorează nivelului înalt al emo iilor pe care le resimt (Gendron, 2007).

2.5. Teama de a nu greşi şi de a se sim i prost fa ă de ceilal i este un alt factor de stres. Acest aspect îl poate determina pe elev să caute scuze pentru a nu realiza o sarcină la şcoală, în fa a celorlal i; în acest fel, el doreşte să-şi apere stima de sine pe termen scurt. Pe termen lung, aceste experien e îi pot afecta starea de bine şi sănătatea, pot duce la scăderea eficien ei, a motiva iei intrinseci şi la deteriorarea stării de spirit. Un exemplu concret poate fi ora de educa ie fizică şi sport; în cadrul acesteia, elevul trebuie să demonstreze în fa a colegilor care sunt abilită ile sale motrice, ceea ce poate genera situa ii de nesiguran ă, anxietate, stres, precum şi comportamente de 
evitare în cazul unei persoane mai pu in abile motric. Potrivit specialiştilor, aceste aspecte derivă din teama de a nu greşi şi de a se sim i prost, gândindu-se la ce ar putea spune sau gândi ceilal i colegi despre el. O cercetare derulată în acest context a avut în vedere analiza efectelor pe care controlul climatului motiva ional şi feedbackul pozitiv, verbal şi nonverbal le au asupra elevilor de 12-13 ani care participă la orele de educa ie fizică din primul an de studiu de învă ământ secundar (Silveira Torregrosa, Moreno Murcia, 2015). Au fost lua i în considerare factori de influen ă precum teama de a nu greşi, motiva ia intrinsecă şi nevoile psihologice de bază, aceştia constituind fundamentul activită ilor cu elevii. Teama de eşec a fost evaluată cu ajutorul inventarului de evaluare a erorii în raport cu randamentul (Conroy, Willow \& Metzler, 2002), care abordează cinci categorii de factori: 1. teama de a experimenta ruşinea fa ă de ceilal i; 2. teama de autoevaluare negativă; 3. teama fa ă de un viitor nesigur; 4. teama de a nu pierde interesul arătat de ceilal i; 5 . teama de a nu-i deranja pe ceilal i. Rezultatele acestei cercetări semiexperimentale au pus în eviden ă faptul că activită ile de îmbunătă ire a climatului motiva ional şi feedbackul pozitiv au condus la diminuarea efectelor negative generate de teama de eşec.

\section{Concluzii}

Excursul articolului în problematica stresului în mediul şcolar a presupus prezentarea succintă a principalelor aspecte teoretice abordate în cercetarea acestui fenomen şi ilustrarea câtorva factori de stres considera i a fi specifici contextelor educa ionale. O mai bună în elegere a ceea ce presupune expunerea la stres a elevilor în mediul şcolar va permite cadrului didactic să aleagă strategii de interven ie utile pentru îmbunătă irea randamentului şcolar şi a climatului clasei (unde disfunc iile pot reprezenta şi cauze determinante pentru violen a şcolară). Un aspect specific cercetărilor privind stresul în mediul educativ constă în identificarea câtorva factori de stres considera i a fi specifici contextului şcolar sau academic şi care derivă, în principal, din natura „contractului de învă are”: data de depunere a unor lucrări, participarea la teste sau examene într-un timp determinat, realizarea unor lucrări în grup, expunerea unor lucrări în fa a colegilor, neîn elegerea unor no iuni sau con inuturi predate în clasă, timp limitat pentru a se achita de obliga iile şcolare/ academice etc. Factorii de stres care se pot asocia cu natura interac iunilor din clasă se referă la ambientul fizic dezagreabil, lipsa de stimulare a elevilor, competi ia în cadrul grupului, natura defectuoasă a rela iilor interpersonale (profesor-elev sau între elevi), gestiunea vorbitului în public, probleme sau conflicte cu profesorii sau cu colegii etc.

Exemplele de studii şi cercetări privind impactul anumitor factori de stres în 
mediul educativ pe care le-am prezentat au pus în eviden ă faptul că, în sistemele educa ionale, inclusiv în sistemul şcolar românesc, există un nivel ridicat de stres privind supraîncărcarea (cantitatea mare de informa ii de asimilat într-un timp limitat) sau evaluarea prin examinare (evaluarea na ională şi bacalaureatul). Factorii care generează stres în mediul educativ afectează percep ia privind propriile nevoi psihologice ale celui care înva ă (competen a, autonomia, rela ia cu ceilal i) şi în cele din urmă randamentul şcolar. Ca urmare, se impune ca interven iile privind prevenirea sau diminuarea stresului şcolar să constituie prioritate în cadrul măsurilor de politici educa ionale privind dezvoltarea curriculară, organizarea evaluărilor şcolare, formarea cadrelor didactice.

\section{REFERIN E BIBLIOGRAFICE}

ACC. (2015). The Social Readjustment Rating Scale An inventory of common stressors.

http://www.acc.com/aboutacc/newsroom/pressreleases/upload/srrs.pdf.

Bados, A. (2008). Miedo a hablar en público. Universidad de Barcelona.

http://diposit.ub.edu/dspace/bitstream/2445/6323/1/MHP.pdf 19/09/2011.

Bandura, A. (1997). Self-efficacy: The exercise of control. New York: W.H. Freeman.

Barraza, A. (2008, 7 de mayo). ¿La escuela te estresa?. PsicoPediaHoy, 10(11). http://psicopediahoy.com/estres-en-la-escuela/.

Bora, A.-A. (2007). Modalită i de prevenire şi combatere a stresului la elevii şcolii de agen i de poli ie.

http://www.e-scoala.ro/psihologie/modalitati_prevenire_combatere_stres.html. Ceballos, E., Correa, A. D., Vega, A., Correa, N., Gorostiza, A., Hernández, H., \& Batista, L. (2002). An Inventory of conflictive situations in Secondary School: devising an instrument to assess the conflict in school. European Conference on Educational Research, Lisabona.

Chandler, L. A. (1985). The stress Response Scale: A manual. Universitatea din Pittsburgh.

Clinciu, A., Cocorada, E., Pavalache-llie, M., \& Rodica, M. (2008). Analyse comparative du stress de l'évaluation. Actes du 20e colloque de l'ADMEEEurope, Universitatea din Geneva.

https://plone.unige.ch/sites/admee08/communications-individuelles/m-a2/ m-a2-1.

Conroy, D. E., Willow, J. P., \& Metzler, J. N. (2002). Multidimensional fear of failure measurement: The performance failure appraisal. Journal of Applied Sport Psychology, 14, 76-90.

Cramer, P., \& Block, J. (1998) Preschool antecedents of defense mechanism use in young adults: a longitudinal study. Journal of personality and Social 
Psychology, 74(1), 159-169.

Cramer, P. (1987). The development of defense mechanisms. Journal of Personality, 55(4), 597-614.

Esparbès-Pistre, S., Bergonnier-Dupuy, G., \& Cazenave-Tapie, P. (2015). Le stress scolaire au collège et au lycée: différences entre filles et garçons. Éducation et francophonie 432 (2015): 87-112. DOI: 10.7202/1034487ar.

García-Calvo, T., Sánchez, P. A., Leo, F. M., Sánchez, D., \& Amado, D. (2011). Incidencia de la Teoría de Autodeterminación sobre la persistencia deportiva. Revista Internacional de Ciencias del Deporte, 25(7), 266-276. DOI:10.5232/ ricyde2011.02502. h.

García-Ureta, I., Toral-Madariaga, G., \& Murelaga-Ibarra, J. (2012). Comunicadores resonantes, comunicadores eficaces. Flujo y credibilidad del comunicador. Revista Latina de Comunicación Social, 67. La Laguna (Tenerife): Universidad de La Laguna, p.99-124. http://www.revistalatinacs.org/067/949_UPV/ 05_Irene.htmI DOI: 10.4185/RLCS-067-949-099-124 / CrossRef link.

GENDRON, B. (2007, Aug.). Capital émotionnel filles-garçons: quelles différences à l'école?. Universitatea din Strasbourg. p. 1-12, 2007.

https://halshs.archives-ouvertes.fr/halshs-00193214.

Institutul de Ştiin e ale Educa iei. (2016). Violen a în şcoală. Studiu pilot privind metodologia de analiză a fenomenului violen ei în şcoală. Bucureşti.

Krashen, S. (1985). The Input hypothesis: issues and implications. 4.ed. New York: Longman.

Lazarus, R. S. (1966). Psychological stress and the coping process. New York: McGraw-Hill.

Madders, J. (1987). Relax and be happy. Union Paperbacks.

Orejudo, S., Fernández-Turrado, T., \& Briz, E. (2012). Resultados de un programa para reducir el miedo y aumentar la autoeficacia para hablar en público en estudiantes universitarios de primer año. Estudios sobre educación, vol. 22/ 2012, p. 199-217.

Sherer, M., Maddux, J. E., Mercandate, B., Prentice-Dunn, S., Jacobs, B., \& Rogers, R. W. (1982). The self-efficacy scale: construction and validation. Psychological Reports, 51, 663-671.

Silveira Torregrosa, Y., \& Moreno Murcia, J. A. (2015). Miedo a equivocarse y motivación autodeterminada en estudiantes adolescentes. Cuadernos de Psicología del Deporte, 15(3), 65-74. http://revistas.um.es/cpd/article/view/ 244491/185281.

Studii OCDE privind evaluarea şi examinarea în domeniul educa iei. România. 2017. UNICEF.

http://www.unicef.ro/publicatii/studiile-ocde-privind-evaluarea-si-examinareain-domeniul-educatiei/. 
Wilson, P. M., Rogers, W. T., Rodgers, W. M., \& Wild, C. T. (2006). The Psychological Need Satisfaction in Exercise Scale. Journal of Sport \& Exercise Psychology, 28, 231-251.

https://selfdeterminationtheory.org/SDT/documents/2006_WilsonRogers Wild_JSEP.pdf.

The online version of this article can be found at: http://revped.ise.ro/category/2017-en/

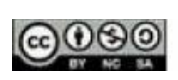

This work is licensed under the Creative Commons Attribution-NonCommercial-

ShareAlike 4.0 International License.

To view a copy of this license, visit http://creativecommons.org/licenses/by-ncsa/4.0/ or send a letter to Creative Commons, PO Box 1866, Mountain View, CA 94042, USA.
Versiunea online a acestui articol poate fi găsită la: http://revped.ise.ro/category/2017-ro/

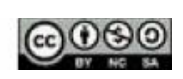

Această operă este pusă la dispozi ie sub licen a Creative Commons AttributionNonCommercial-ShareAlike 4.0 International.

Pentru a vedea o copie a acestei licen e, vizita $i$ http://creativecommons.org/licenses/by-ncsa/4.0/ sau trimite i o scrisoare către Creative Commons, PO Box 1866, Mountain View, CA 94042, SUA. 